\title{
Abordagens e discussões sobre o espaço museal, a patrimonialização e a comunicação cultural no estudo comparativo entre Museu e Sala de Milagres do Santuário do Bomfim, em Salvador, Bahia
} Genivalda Cândido da Silva ${ }^{1}$

\begin{abstract}
Resumo:
A pesquisa realizada teve como objetivo analisar como as práticas exvotivas, presentes no Santuário do Bomfim, se vinculam à cultura popular dos pagadores de promessa que são inerentes as classes sociais que transitam livremente pela sala de milagres, e os objetos ex-votivos que são museografados no Museu dos Ex-votos. notou-se a necessidade de realizar a interpretação e elucidação das novas dimensões e significados culturais da arte e da religiosidade popular abordando os seguimentos conceituais dos termos que circundam e representam a história e formação do Santuário do Senhor do Bomfim, como: o sacro e o profano, a estética, a folkcomunicação e a museologia que são temas transversalizados que, ao final dos estudos percebemos estarem intrinsecamente vinculados. Elucidando assim a compreensão, como se dá a sua contextualização com os ambientes trabalhados e as diferentes formas comunicacionais, a qual, é propiciada nos espaços abordados na pesquisa.
\end{abstract}

Palavras-chave: ex-votos, sala de milagres, Museu dos Ex-votos, patrimonialização, comunicação, Santuário do Senhor do Bomfim.

\section{Abstract:}

${ }^{1}$ Museóloga. Mestra em Museologia pela Universidade Federal da Bahia (UFBA). Integrante do Grupo de Estudos sobre os Cibermuseus e Núcleo de Pesquisas dos Ex-votos (NPE), onde desenvolve atividades de pesquisa e tutoria. Atua como parecerista do Intercom Nacional e Regionais. Parecerista da Revista HOMINUN e Revista ECO-Pós. Vice-coordenadora do Projeto de Extensão Circuito dos Clássicos. 
The research carried out had as objective to analyze how the ex-votive practices, present in the Sanctuary of the Bomfim, are linked to the popular culture of the payers of promise that are inherent to the social classes that transit freely through the room of miracles, and the ex-votive objects that Are museograted at the Museum of Ex-votos. It was noted the need to interpret and elucidate the new cultural dimensions and meanings of art and popular religiosity by addressing the conceptual followings of the terms that surround and represent the history and formation of the Sanctuary of the Lord of Bomfim, such as the sacro and the Profane, aesthetics, folkcommunication and museology that are cross-cutting themes that, at the end of the studies, we perceive to be intrinsically linked. Thus elucidating the understanding, as it gives its contextualization with the environments worked and the different forms of communication, which is propitiated in the spaces covered in the research.

Keyword: ex-votos, hall of miracles, Museum of Ex-votos, patrimonialization, communication, Sanctuary of the Lord of Bomfim.

\section{Espaço e localização da pesquisa}

A cidade do Salvador foi erguida sobre bases tradicionais portuguesas. Bases essas constituídas com muito suor, sofrimento, desbravamento, vidas e fé. As crendices no divino, independente de quaisquer que sejam, estão enraizadas na gênese do povo brasileiro, onde muitas vezes o espaço arquitetônico serve para propagar as manifestações de fé. De fato, desde o século XVII até a primeira metade do século $X X$, a fé foi uma das forças motrizes de construção do nosso país, principalmente quando falamos das arquiteturas religiosas (ermidas, templos, igrejas, basílicas), que dentre elas está a Basílica do Senhor do Bomfim, ${ }^{2}$ erguida a partir da fé e resultante de uma promessa.

Assim como os objetos de fé e arte contidos em seu interior, a Basílica é também conhecida por ser um ex-voto, por ter

\footnotetext{
${ }^{2}$ Popularmente e internacionalmente conhecida como Igreja do Senhor do Bomfim.
} 
sido edificada a partir de uma promessa. Os ex-votos são objetos representativos da fé das tradições portuguesas, onde são conhecidos como "milagres". No Brasil ganharam diferentes significações: "graças", "promessas", "agradecimentos" e também "milagres". Partindo dessa premissa, e tendo na Bahia, especificamente em Salvador, um ícone popular patrimonial da cultura e da fé, a Basílica do Bomfim é vista aqui como um espaço onde as práticas religiosas e os comportamentos de vários sujeitos são reconhecidos e representados.

Então, a partir dessa abordagem, nos respaldamos na estética, no sagrado (no âmbito da fé), da religiosidade (do erudito contrapondo com o paradoxo do profano/popular) para tecer questionamentos e discussões acerca de dois espaços singulares da Basílica $^{3}$ do Bomfim: a sala de milagres e o museu dos Ex-votos.

\section{Devoções ao Senhor do Bomfim: Portugal e Brasil}

A devoção ao Senhor do Bomfim teve início em Setúbal Portugal, de acordo com Carvalho Filho (1923), é datada de antes do século XVII, na Ermida do Anjo da Guarda. ${ }^{4}$ Segundo Carvalho Filho (1923), a imagem do Senhor Jesus do Bomfim foi encontrada por uma mulher, na cidade de Setúbal. De acordo com a tradição popular, a imagem estava entre pedaços de madeira numa praia e, provavelmente era parte dos restos de algum navio que naufragara.

Percebe-se nessa tradição, a proximidade entre a fé do povo e as vicissitudes de sua vida cotidiana, a presença das aventuras ultramarinas e os perigos que traziam para as pessoas de então. A festa do Senhor do Bomfim de Setúbal, é realizada anualmente no dia 1 을 de novembro. Após os sobreviventes do terremoto de Lisboa de 1755, passarem pelo sofrimento e pânico do desastre natural, o povo fez voto ao Senhor do Bomfim, a graça de vida. Desde então, a devoção, a prática da missa, da

\footnotetext{
${ }^{3}$ A Capela foi elevada a "Basílica Menor" em 1927 pelo Papa Pio XI.

${ }^{4}$ Imagem da Igreja do Senhor do Bom-Fim de Setúbal, registrada no livro a Devoção do Senhor Bom Jesus do Bomfim e sua História, p. 42. na última página. (retirar essa frase, na última página)
} 
peregrinação e da procissão, nessa data, são realizadas como forma de agradecimento e fé.

Diferente do Senhor do Bom-Fim de Setúbal, a imagem do Senhor do Bomfim de Salvador não foi achada sob restos de naufrágio, mas trazida, da cidade de origem portuguesa. Como narrou Carvalho Filho (1923) pelas mãos do Capitão de mar-eguerra Theodózio Rodrigues de Faria, ${ }^{5}$ chegou aqui "uma Imagem semelhante esculpida em cedro com um metro e dez centímetros de altura, e, compondo o conjunto escultórico um aparelho de prata (com barra decorativa, ponteiras, cartela com inscrição INRJ, resplendor, cravas com pedras preciosas, coroa de espinhos, mandorla", segundo França (2003, p. 104). Observa-se que a imagem do Senhor do Bomfim surgiu como uma entidade fortalecida pela adição de elementos diversos, como a lavagem das escadarias da igreja, as fitinhas, o hino, o sincretismo.

$\mathrm{O}$ capitão chegou à Bahia no ano de 1740 e residiu até 22 de janeiro de 1757, ano de seu falecimento. Assim como ocorreu com o fundador da igreja em Setubal, após sua morte o capitão foi sepultado no piso no corpo da Capela do Senhor Bom do Bomfim "para cuja construção tão dedicada e devotamente concorrera após ter fundado em 1745 a devoção ao mesmo Senhor na cidade do Salvador e Bahia de Todos os Santos". (Carvalho Filho, 1923, p. 7). A origem da Igreja do Bomfim adveio de um milagre, no qual, juntamente com sua tripulação, saírem ileso de uma tormenta, em alto-mar. O Capitão Theodózio fez a promessa de que, chegando à Cidade do Salvador, ergueria uma ermida em agradecimento. Então, no ano de 1740, já residindo na capital, deu o início à devoção do Senhor do Bomfim e início da construção da Igreja.

Para a construção, manutenção e administração da Igreja foram instituída uma associação de leigos católicos, com a intenção única de manter a igreja e o culto ao Senhor do Bomfim na Bahia, provendo de desenvolvimento, conservação e manutenção dos

\footnotetext{
${ }^{5}$ Capitão-de-mar-e-guerra, dono de duas naus portuguesas, que traziam especiarias da Índia para o Brasil.
} 
bens que constituíam o patrimônio da Devoção. A ideia de materializar um ideal com a arquitetura é o de transformar um sítio em lugar, ou seja, descobrir os significados e potenciais presentes no espaço, dar vida, dar esperança, acolher quem precisa e confortar com fé quem assim o necessita. Com essas intenções, foi então idealizada e construída a Capela do Senhor do Bomfim. Seguindo o estilo arquitetônico das construções religiosas portuguesas do século XVIII.

\section{Da lavagem ao pagamento de promessa: a devoção ao Senhor do Bomfim}

A religião popular é uma manifestação coletiva, geradora de fortes sentimentos de identidade entre seus membros. Não é apenas um meio de repassar sua fé, mas de criar e recriar meios de difundir e perpetuar os seus valores, crenças e memórias. Pode-se dizer que a Lavagem do Senhor do Bomfim, e os pagamentos de promessas, são processos de manifestações populares que se encontram em um mesmo ambiente, porém contextualizados e cultuados de formas diferentes, mas que se transversalizam em um momento, o do pedido e do agradecimento, quando sala de milagres, museu e culto se consagram.

Durante o período colonial, a presença de religiosos (jesuítas, padres) estava dispersa, principalmente nas áreas rurais, sujeito mais à dominação dos senhores de engenho e outros latifundiários, em cujas propriedades eram mais capelães que autoridade de seus bispos. Com seus ensinamentos e pregações, forneciam uma ideologia ancorada na teologia que justificava e dava suporte aos padrões socioeconômicos existentes, à exceção dos jesuítas, como escreve Freyre (1990), numa visão sociológica:

Clérigos, e até mesmos frades, acomodaram-se, gordos e moles, às funções de capelães, de padres-mestres, de tios-padres, de padrinhos de meninos: à confortável situação de pessoa da 
família, de gente da casa, aliado e aderente do sistema patriarcal. (p. 196).

O catolicismo no Brasil tem o seu início não com a cruz fincada com a chegada de Pedro Álvares Cabral, mas quando os artífices da Colônia atravessavam os oceanos empenhados na propagação da fé. Quando havia acompanhamento dos párocos, atrás da conquista, estava vigilante a igreja católica, e com ela, instruções educativas, difusão das artes e apresentação de uma nova manifestação cultural popular, as festas aos santos de devoção. A peregrinação cristã que advém do século $V$ é também conhecida como romaria pelo fato de consistir, inicialmente, na ida de devotos de suas localidades para Roma. Os fiéis acreditavam que o poder de Deus se manifestava nos lugares visitados por Jesus Cristo, pelos santos ou pela Virgem Maria, ou também nos lugares onde eles teriam aparecido em visões, onde estão guardadas as suas relíquias, ou ainda onde aconteceu algum milagre. As práticas religiosas, como as romarias, indicam experiências humanas repletas de significados, tendo uma nítida dimensão espacial, (re)organizando o espaço e modificando a paisagem urbana

A fé ao Senhor do Bomfim é notória no povo baiano, em todas as classes sociais, desde os tempos da Colônia até a atualidade. Não importando se o ato de lavar a igreja ou a escadaria fosse imposto por senhoras, o certo é que era feito com prazer, zelo e devoção, por quem praticava o ato. A denominada "Lavagem do Bomfim" é capaz de, conforme a contextualização apresentada, cristalizar, desmanchar, confraternizar, profanar, ritualizar ou sacralizar a fruição coletiva do momento em que é realizada.

$\mathrm{Na}$ "Lavagem do Bomfim", o pagamento de promessa não é realizado com um signo, um ex-voto em madeira, parafina, imagens ou outros, mas com o próprio corpo, com a exaustão do percurso, na caminhada, da água de cheiro das baianas do sincretismo, do perfume, das flores, da própria lavagem, com a finalidade de receber a benção ao final, e ter o sentimento de promessa cumprida 
Abordagens e discussões sobre o espaço museal...

\section{A museologia - museu; a estética e a sala de milagres: congruências e comunicação}

Desde o seu surgimento a museologia, foi (re)criada sucessivamente ao logo dos tempos. Primeiramente, estava vinculada aos objetos, colecionadores e coleções para, em meados do século $X X$, ser separada da museografia, e, posteriormente tornar-se uma disciplina científica. Stránský (2008, p. 28) faz a observação de que "por muito tempo que a museografia tem sido apresentada como o que agora se refere à Museologia, mas, de acordo com a própria etimologia do termo, deveria apenas referirse aos relatos descritivos do trabalho de museus." Sobre o pensamento de Stranský (2008), em relação à distinção entre museu, museografia e museologia, ele propôs que "[...] museografia é a soma de todo trabalho que não é de caráter criativo, mas que projeta cada criatividade, trabalhos exploratórios no âmbito das atividades práticas de museus" (p. 28). Nota-se que há a necessidade de uma distinção entre as finalidades das áreas, porém estas, estão intrinsecamente liagadas.

De acordo com Cauquelin (2005), "a arte oscila na direção de uma ordem que ignora sua expressão para se estabelecer no discurso, o logos, no qual se refletirá, mantendo a distância pela razão ou mesmo pelo raciocínio" (p. 28). Embora a palavra estétic e seu conceito moderno tenham sido desenvolvidos por $A$. Baumgarten $^{6}$ no século XVIII para denominar e definir um campo de estudos que deveria tomar a percepção e as sensações como princípios de um conhecimento sensível do mundo, pensadores

\footnotetext{
${ }^{6}$ Baumgarten é um dos principais representantes do lluminismo. É um filosofo alemão do século XVIII, foi o primeiro a usar o termo estética e também a ministrar o curso de estética. Ele segue a mesma linha de Descartes, pois, para ele, a alma é o que nos permite ter consciência da nossa existência, ou seja, para ele a razão é o que nos permite existir. Divide a razão em duas faculdades, a faculdade superior e a faculdade inferior; a estética só é possível por causa dessa faculdade inferior. Ele afirma que, a partir da nossa posição, podemos perceber, de modo claro ou obscuro, as marcas distintivas.
} 
como Kant, Hegel e outros submergiram de volta à estética, como filosofia da arte, a essência da filosofia geral

Esse questionamento remete obrigatoriamente a um conceito e a busca por uma definição que seja compreensível e aceitável a todos, que distinga as coisas identificáveis numa extensão, por outro lado, entende-se que a essência, núcleo de definição, não está na "coisa", mas sim no conteúdo da representação que se faz dela. Encontrar propriedades comuns e necessárias para identificar as características da arte numa coisa ou num evento, sempre foi o desafio dos chamados essencialistas, ${ }^{7}$ que acreditam que os objetos de arte possuem propriedades imanentes que lhes são intrínsecas. A existência de uma áurea comum em todos os objetos considerados artísticos constitui-se em uma das bases da teoria essencialista, que são tributárias do pensamento clássico acerca da identidade, das coisas que são iguais a si mesmas - fundamento do pensamento racional.

Os ambientes da Basílica, assim como da Sala de Milagres, possuem chão revestido em mármore, material que sempre esteve presente em edificações referenciadas como sacras ou aferidas a algum tipo de notoriedade ou valor social. O local passou por muitas reformas ao longo de sua existência. Em um relato de Carlos A. Carvalho (1915), sobrinho do fundador do Museu dos Ex-votos, ele diz que a primeira reforma da igreja se deu por volta de 1800, quando aconteceram as obras das torres. Isso por conta de raios, que em 1772, atingiram a torre, como afirmou o autor

As Torres da Capella foram feitas posteriormente ao edifício, porquanto este recebendo a imagem em 1754, só foram concluídas em 1772. Por duas vezes foram ellas attingidas pela acção dos raios, resultando da última vez a torre da direita cahir

\footnotetext{
${ }^{7} \mathrm{O}$ essencialismo é um "conteudismo" proveniente do hábito de se crer que a substância (sub stare = estar sob) das coisas existe como uma realidade alcançável pelo pensamento, emprestando-lhe um significado que vale sempre mais do que o significante (sua aparência superficial). $O$ essencialismo é um resto de metafísica que atribui qualidades subjetivas a coisas do mundo real.
} 
completamente. O Dr. Freire Filho collocou em uma dellas um para-raios e outro no cruzeiro do fundo da capella. (p. 7-8).

Apesar de vários dados, referentes a reformas, em nenhum momento, a Sala de Milagres foi real e diretamente referenciada. Observamos que as reformas foram realizadas no geral, em todo corpo da igreja, dentre as quais, uma foi para a transformação de uma das Salas de Milagre em Museu, Museu dos Ex-votos.

A Sala de Milagres encontra-se no final do corredor lateral direito da igreja, com dois acessos diretos, sendo um pela própria igreja. O teto possui frisos em gesso no centro, em um total de seis frisos, são recentes. Talvez por esse motivo tenha sido o local destinado para receber os ex-votos de parafina que ali ficam em exposição. A Sala de Milagres é um ambiente que, no período de sua criação, também servia de local para acomodação dos romeiros em pagamentos de promessas. Atualmente, mantém-se a Sala, e a área que era reservada, serve de apoio para os visitantes que vão participar dos cultos ao Senhor Morto. A estética da Sala de Milagres é livre, fluida. Sua criação se deu desde o início da edificação da igreja. A Sala provém da preocupação da devoção em construir um espaço "sagrado" para fortalecer a fé dos fiéis e incitar o imaginário dos descrentes.

O desejo de preservar os documentos da fé, da devoção. Lopes e Carvalho decidem então dar início à criação de um ambiente onde os objetos de maior valor estético e material e que fossem "únicos" tivessem um local apropriado para adequação e guarda. Assim foi criado o Museu dos Ex-votos do Santuário do Bomfim. A representação da fé através da arte, dos signos da estética está inserida em destaque na comunicação cultural e popular que permeia e vive no Santuário do Bomfim. Ela não é uma performance baseada na interpretação de atores, mas sim, é a união de uma disposição de "coisas" que foram colocadas num espaço por um fiel, com a intenção de torná-las acessíveis a todos os atores que assim o desejassem. Esse fator pode vir a ter tensões, mas isso é sempre presente quando se refere à 
religião/cultura/objetos/pessoas, visto que, em certos momentos, pode haver um encontro da racionalização da visão na comunicação, da busca da significação e da arte. A comunicação estética torna-se, nesse contexto, a protagonista da transição dos tempos, afirmando a legitimidade cultural da arte popular do passado que se faz intrínseca no presente e fundamental para o futuro.

\section{Comunicação e Folkcomunicação no Santuário do Bomfim}

É correto afirmar que toda ciência advém de um período histórico e dos estudos referentes às atividades existentes, das necessidades culturais de uma sociedade, em que vários fatores contribuem para dar forma, conteúdo, a exigências que abrangem, desde os signos, à religiosidade e, principalmente, à forma pela qual é aceita e difundida. Tem-se um vínculo interno com o passado, como origem, isto é, com um passado que não interrompe nunca, que é, conservado e está presente nas memórias, lembranças, nos objetos e culturas (materiais ou não). Isso tudo, muitas vezes, não permite a distinção da diferença temporal e da compreensão do presente, no presente vivido, enquanto único modo de vida. De acordo com Chauí (2001),

[...] se refere a um momento passado imaginário, tido como instante originário que se mantém vivo e presente no curso do tempo, isto é, [...] visa a algo tido como perene (quase eterno) que traveja e sustenta o curso temporal e lhe dá sentido, [...] pretende situar-se além do tempo, fora da história, num presente que não cessa nunca sob a multiplicidade de formas ou aspectos que pode tomar. Não só isso. A marca peculiar é a maneira como ela põe a transcendência e a imanência do momento fundador: a fundação aparece como emanando da sociedade (em nosso caso, da nação) e, simultaneamente, como engendrando essa própria sociedade (ou a nação) da qual ela emana. (p. 5-6). 
Com a Folkcomunicação, acontece o mesmo. Ela é uma área dos estudos da comunicação que está presente entre os humanos, porém, não era reconhecida e difundida, como a maioria das produções científicas de cunho nacional que transversalizam com o popular. Essa peculiaridade constitui um traço específico dessa área, já que as produções científicas literárias dos intelectuais brasileiros são constantemente submetidas a um "olhar cultural" conservador, o que muitas vezes, faz com que sejam desmerecidos ou passem despercebidas pela sociedade acadêmica e popular. Nossa sociedade é composta por uma gama de grupos que atuam ativa ou passivamente, e a comunicação se torna um problema fundamental, já que há uma divisão heterogênea e cultural quanto às etnias, divisões sociais e especiais (igreja, estado, indústrias, etc.) que são decorrentes das estruturas organizacionais de desenvolvimento vigentes.

Faz-se necessário e cada vez mais que conheçamos o Brasil. Que, sobretudo, conheçamos a gente do Brasil. E então, se recorremos aos livros dos que colheram as tradições orais, e os costumes da nossa gente, desespera a falta de valor cientifico dessas colheitas. [...]. Nós precisamos, de moços pesquisadores, que vão à casa do povo recolher com seriedade e de maneira completa o que esse povo guarda e rapidamente esquece, desnorteando pelo progresso invasor. (Carlini, 1997, p.24).

É na continuidade dos seus interesses pelo passado e com sua investigação sobre as tradições construtivas, desde o período colonial, $^{8}$ que podemos pensar a Folkcomunicação em sua trajetória, como afirma Carneiro (2008): "somente as formas em que há elementos genuinamente populares permanecem." Essa reflexão acerca da Folkcomunicação possibilita pensar o ressignificar das mensagens da comunicação de massa e a capacidade de criar e recriar meios próprios de expressões dos

\footnotetext{
${ }^{8}$ Inclusive na valorização dos ofícios artesanais nos canteiros de restauro, nas cantigas de roda, no fazer, na escrita, nas comidas.
} 
grupos marginalizados. Essa abordagem desejou considerar que os movimentos populares, expressos nos grupos marginalizados, são capazes de reproduzir concomitantemente o padrão básico da cultura dominante e sobressair, desfazendo, assim, a visão imperativa de que a cultura erudita é determinante para a cultura marginalizada, pois sabe-se que o maior contributo da Folkcomunicação é a valorização dos diferentes modos com que os grupos marginalizados e de massa produzem e difundem sua cultura. Conforme assinala Gobbi (2007):

O que percebemos na atualidade é uma busca, nem sempre perceptível pelos menos atentos, de ações que evidenciam costumes, credos e outras formas de participação social, presentes nas manifestações diversas e que repercutem intensamente nas camadas mais populares. São as formas culturais de um orbe específico e singular, mas não individual, incorporadas ao universo simbólico das comunidades periféricas, formando um mosaico de revelações singulares, mas não únicas, que rompe o isolamento social a que comunidades inteiras são submetidas por conta da chamada 'globalização'. (p. 22)

Nesse contexto, pode-se trazer para a abordagem os exvotos, os milagres, as promessas, as graças alcançadas, manifestações que advieram da religião do povo, das raízes da colonização, de acordo com Benjamim (2003):

A prática mais tradicional da comunicação, nas devoções populares, é a entrega do ex-voto. No ex-voto paga-se o compromisso de natureza contratual com o santo. A entrega do ex-voto é, porém, a publicização da intervenção - o milagre ou, mais modestamente, a graça alcançada - mensagem cujos receptores são os outros devotos ou pessoas que circunstancialmente passem ou visitem o local da devoção. Quanto mais ex-votos depositados, mais provados ficam os benefícios alcançados pela intercessão do santo, o que faz crescer a fama e despertar o interesse de novos devotos. (p. 43-44) 
Consiste, assim que, o ex-voto fez e faz parte de toda essa evolução, tanto artístico-pictórica quanto comunicativa, interagindo do passado com o presente, mantendo diálogos com todos os tipos variados de grupos sociais.

\section{Diálogos possíveis: a comunicação museológica e a}

\section{Folkcomunicação no Santuário do Bomfim}

A partir dos diálogos apresentados até o momento, imagem-função-escrita, é possível afirmar que a leitura da imagem contribui como um documento que auxilia na formação da comunicação existente na Sala de Milagres, uma vez que, por meio das imagens, é concebível fazer uma "leitura" contínua, que possibilita ao sujeito construir, sua visão do mundo do pagador de promessas e situar-se nele.

Os espaços envolvem as pessoas e estas se envolvem num misto de metáforas e narrativas, que vão muito além de sua geometria espacial, pois coloca o observador em uma realidade virtual envolvendo-o em situações e narrativas específicas, nas quais a percepção do "personagem fruidor" assimila detalhadamente o espaço. Esse observador não realiza uma leitura de maneira distanciada, mas inserida dentro do que se chama de realidade virtual; isso porque o visitante, turista ou observador se insere como pagador de promessas com o objeto no seu contexto natural. Em relação às leituras dos objetos nesse espaço, podemos traduzi-lo de acordo com leituras antepassadas: na cruz se juntam o céu e a terra, nela se confundem o espaço e o tempo. É a ponte entre dois mundos, o material e o espiritual. Notamos que, um ponto interessante desse símbolo é que ele sofreu uma mudança repentina histórica: antes, referenciado como um vergonhoso símbolo de suplício, depois, passou a ser símbolo da redenção e vitória sobre a morte, não sem passagem pelo suplício e o sofrimento de um homem, Jesus Cristo. 


\section{Considerações Finais}

O Santuário do Senhor Bom Jesus do Bomfim não se encontra em um tempo ou espaço esquecido, ao contrário, pode-se afirmar que é um espaço privilegiado, rico em arte, cultura, fé e comunicação, que vem se ressignificando ao longo dos séculos, e mesclando a contemporaneidade com objetos antes jamais imaginados serem possíveis em um ambiente sacro/religioso que tem o profano e o popular como propulsores e fontes de toda a sua existência.

Na Sala de Milagres, observa-se que o devoto sente como a existência do santuário como primordial. Ele crê que tudo o que está à sua volta é decorrente da sua fé, da sua crença. E que se ele não mantiver um diálogo direto com o santo nada do que ali está continuará no futuro. Isso se deve ao que foi sugerido, nas questões patrimoniais, culturais e folkcomunicacionais.

Notou-se durante o período da pesquisa que os fiéis, após o término das missas, se dirigem para a sala, na intenção de ver os ex-votos, de ler os registros dos milagres, e muitos apenas ficam parados na sala como se estivessem à "espera de uma graça". As possibilidades comunicacionais presentes no espaço são muitas. Como ele difere, com uma aura que permeia entre a fé, a sacralidade e o profano, e uma liberdade que podemos denominar "Folkcomunicacional", que é expressa de maneira aberta, sem cobrança de taxa, ou a presença de um intermediário, que são os dois primeiros diferenciais entre museu e Sala de Milagres.

O Museu é um embrião se comparado à Sala de Milagres. No entanto, este fator não influênciou quando se tratou do Museu como grande exponencial diferenciador nos questionamentos sugeridos. Quando há referências a Museus, sempre há questionamentos dialogando com eles. No Museu do Ex-votos não foi diferente. Observou-se que as coleções expostas no local são de cunho popular, muitas são registros da fé, de graças alcançadas, outras foram doações de fiéis. 
O que se colocou à pauta foram questionamentos referentes à forma expositiva e "erudita" em quase sua totalidade. Muitos objetos são tratados como se estivessem em uma exposição da arte sacra, quase que intocáveis.

Tratamos do Museu como uma Sala de Milagres, com a ausência de uma museografia e certa cenografia, apesar de não ser identificada qual. Ainda assim, foi dificultoso compreender o museu, pois o mesmo não possui um estilo determinado. Também o fator acessibilidade chamou atenção na pesquisa, visto que, para se chegar a ele, determinado esforço. 0 espaço museal se mostra impraticável para pessoas com deficiências motoras nas pernas e cadeirantes, não somente na sua entrada, mas no próprio circuito.

Muitos fatores estão presentes no Museu: taxas, escadas, mediador, vitrines de parede e de chão, museografia, ${ }^{9}$ indícios de que o local tentou se adequar aos sistemas museais, porém não obtendo de todo êxito. O fator primordial é de que não há uma livre comunicação, interação espaço-objeto-visitante.

A Tabela de dados comparativos, traz em síntese, a aproximação e o distanciamento entre os dois ambientes, quando enquadrados no patrimônio cultural, dentro das perspectivas museológica e de Folkcomunicação.

\section{Referências}

BENJAMIN, Roberto. Devoções populares não canônicas na América Latina: uma proposta de pesquisa. Revista Internacional de Folkcomunicação. v. $\mathbf{n}$ 1. 2003. Disponível in: http://www.uepg.br/revistafolkcom/anteriores/revista01.pdf . Acessado em 22 de maio de 2016.

\footnotetext{
${ }^{9}$ Apesar de o local ser citado no GMB como não possuir uma museografia, como apresentado no decorrer da pesquisa, mesmo assim, tal fator é observado no espaço.
} 
Carlini, A. (1997). Martin Braunwieser na viagem da missão de pesquisas folclóricas (1938): diário e cartas. Revista de História FFLCH- USP, São Paulo. 1994, v. 1, n. 1. In: I Simpósio LatinoAmericano de Musicologia, Curitiba.

Carneiro, E. (2008). Dinâmica do Folclore. São Paulo: Civilização Brasileira. (não sei porquê saiu esse ano, mas a data correta do livro q tenho e utilizei é 2008)

Carvalho, C. A. de. (1915). Tradições e Milagres do Bomfim. Obra seguida de Interessante Resenha Histórica da Península de Itapagipe. Salvador: Typ. Bahiana.

Carvalho Filho, J. E. F. de. (1923). A Devoção do Senhor Bom Jesus do Bomfim e Sua História. Salvador . 2 ed. Reimprimatur: Imprensa Oficial. Bahia.

Cauquelin, A. (2005). Teorias da Arte. (R. Janowitzer, Trad.). São Paulo: Martins Fontes.

Chauí, M. (2001). Mito fundador e sociedade autoritária. São Paulo: Fundação Perseu Abramo.

França, R A. (2003). As cores do Bomfim. Salvador.

Freyre, G. (1990). Casa-grande e Senzala. São Paulo: Circulo do Livro.

Gobbi, M. C. (2007). A mídia das comunidades periféricas: folkcomunicação a mídia dos excluídos. Cadernos de comunicação. Série Estudos, v. 17. Rio de Janeiro. Secretaria Especial de Comunicação Social. II

Stránský, Z. Z. (1980). Sobre o tema "Museologia - ciência ou apenas trabalho prático?" (T. Scheiner, Trad.). Revista Eletrônica do Programa de Pós-Graduação em Museologia e Patrimônio, 1(1), jul./dez. de 2008. 


\section{FIGURAS}

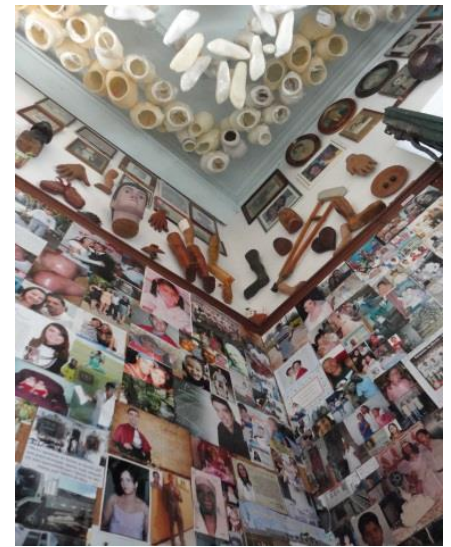

Ex-votos da Sala de Milagres. Fotógrafa: Silva

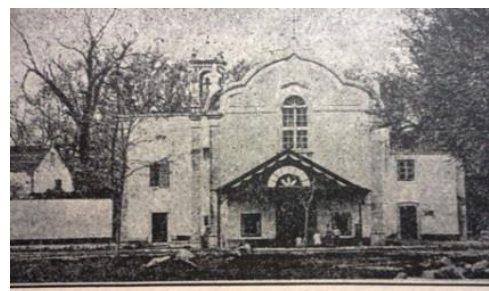

Igreja do S. do Bonfim em Setubal (Portugal)

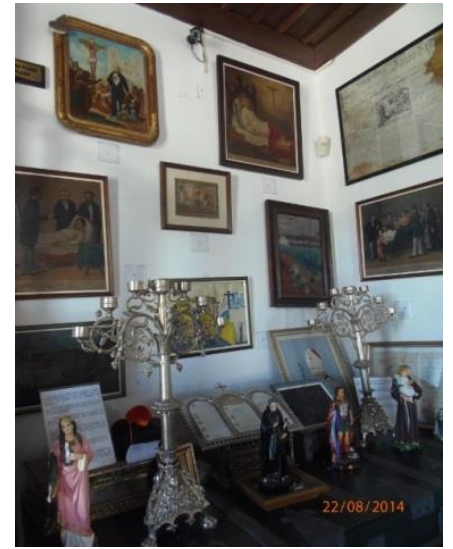

Ex-votos do Museu dos Ex-votos. Fotógrafa: Silva

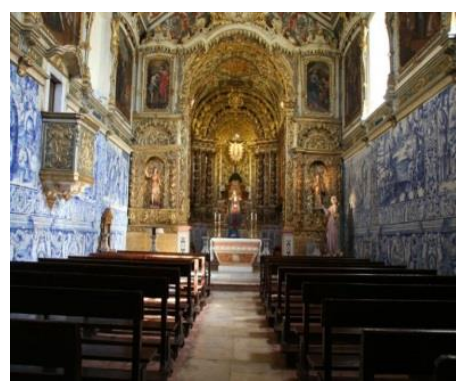

Figura 4. Nave única, altar-mor da Capela do Senhor do Bom-Fim de Setúbal. Fonte: Fotógrafo: Francisco Oliveira, 2013. 
Genivalda Cândido da Silva
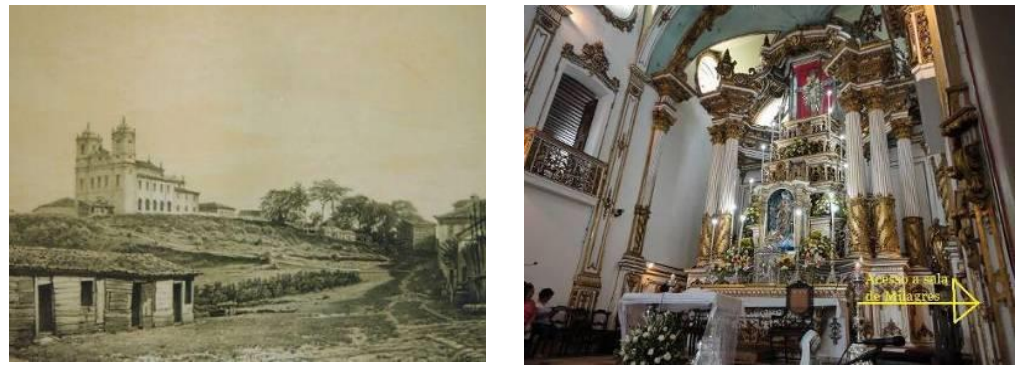

Fonte Fundação Gregório de Altar-mor Igreja do Senhor do Mattos. 2008.

Bomfim, Salvador, Bahia. Flecha direciona para o acesso a sala de Milagres. Fotógrafa: Silva (2014).
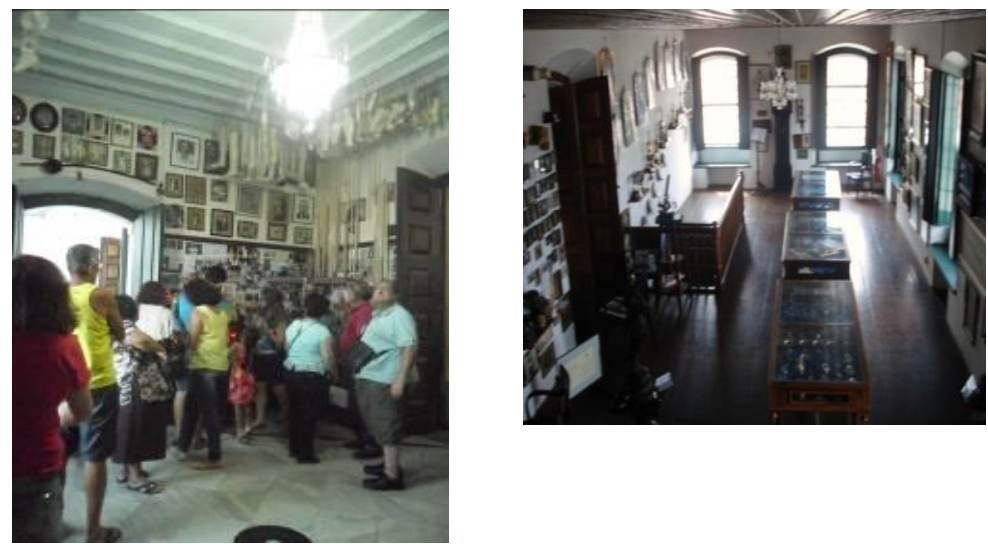

Turistas em visita e fruição na

Visão geral do Museu dos ExSala de Milagres da Basílica do votos. Fotográfa: Silva. 2014 Bomfim, Salvador, Bahia. Fotógrafa: Silva 